\title{
Human Peripheral or Cord Blood Cell Product
}

National Cancer Institute

\section{Source}

National Cancer Institute. Human Peripheral or Cord Blood Cell Product. NCI Thesaurus.

Code C133274.

Cells from human blood or umbilical cord blood for transplantation or infusion. 